\title{
Microscopic investigation of soot and ash particulate matter derived from biofuel and diesel: implications for the reactivity of soot
}

\author{
Anthi Liati · Alexander Spiteri • \\ Panayotis Dimopoulos Eggenschwiler • \\ Nina Vogel-Schäuble
}

Received: 21 May 2012/Accepted: 26 September 2012

(C) Springer Science+Business Media Dordrecht 2012

\begin{abstract}
Investigation of soot and ash particulate matter deposited in diesel particulate filters (DPFs) operating with biofuel (B100) and diesel (pure diesel: B0 and diesel $_{80} /$ biofuel $_{20}$ blend: B20) by means of optical microscopy, scanning electron microscopy, and high resolution transmission electron microscopy (HRTEM) reveals the following: the rapeseed methyl ester biofuel used for this study contributes to ash production, mainly of $\mathrm{Ca}-\mathrm{S}-$ and P-bearing compounds ranging in size between 50 and $300 \mathrm{~nm}$. Smaller ash particles are less common and build aggregates. Ash is deposited on the inlet DPF surface, the inlet channel walls, and in B100-DPF at the plugged ends of inlet channels. The presence of $\mathrm{Fe}-\mathrm{Cr}-\mathrm{Ni}$ fragments, down to tens of nanometers in size within the ash is attributed to engine wear. $\mathrm{Pt}$ particles (50-400 nm large) within the ash indicate that the diesel oxidation catalyst (DOC) upstream of the DPF shows aging effects. Radial cracks on the coating layer of the DOC confirm this assumption. The
\end{abstract}

A. Liati $(\varangle) \cdot$ A. Spiteri - P. Dimopoulos Eggenschwiler Laboratory of Internal Combustion Engines, EMPA,

Swiss Federal Laboratories for Materials Testing and

Research, Ueberlandstrasse 129, 8600 Dübendorf,

Switzerland

e-mail: anthi.liati@empa.ch

N. Vogel-Schäuble

Laboratory of Solid State Chemistry and Catalysis, EMPA, Ueberlandstrasse 129, 8600 Dübendorf,

Switzerland
B100-DPF contains significantly less soot than B20 and $\mathrm{B} 0$. Based on the generally accepted view that soot reactivity correlates with the nanostructure of its primary particles, the length and curvature of graphene sheets from biofuel- and diesel-derived soot were measured and computed on the basis of HRTEM images. The results show that biofuel-derived soot can be more easily oxidized than diesel soot, not only during early formation but also during and after considerable particle growth. Differences in the graphene sheet separation distance, degree of crystalline order and size of primary soot particles between the two fuel types are in line with this inference.

Keywords Diesel soot - Diesel ash .

Soot nanostructure - Graphene $\cdot$ Soot oxidation . Biofuel

\section{Introduction}

The detailed investigation of emissions from diesel engines is gaining importance, on the one hand due to enhanced measures for the reduction of air pollution and on the other through improvement of aftertreatment strategies, engine performance, and fuel efficiency. Given the fact that trucks are operating with diesel fuel and that the demand for personal diesel cars continues to rise, bio-derived fuels have been applied in recent years as an alternative to diesel. Application of biofuels aims primarily at reducing diesel 
particulate matter (PM) and $\mathrm{CO}_{2}$ emissions, in addition to substituting limited oil reserves.

Soot derived from the combustion of diesel fuel is a major air pollutant. A minor fraction of PM produced by diesel engines is inorganic ash. It originates mainly from lubricating oil additives and, to a small extent, from trace metals in diesel fuel, engine wear and corrosion (e.g., Vaaraslahti et al. 2005; Sappok and Wong 2010). Diesel soot particles are, in their majority, a few tens of nanometers in diameter. Diesel ash PM is also of submicron size, sometimes down to a few nanometers, or tens of nanometers large (e.g., Liati et al. 2012 and references therein).

Removal of both soot and ash PM from the exhaust stream of diesel engines is a long-standing goal, accomplished, to a great extent, by means of different exhaust aftertreatment methods. The introduction of diesel particulate filters (DPFs) with a filtration efficiency of 95-99\% has been remarkably successful in this respect. Soot PM trapped in the DPF is oxidized and removed partly continuously during passive regeneration (at temperatures upstream of the DPF at $200-400{ }^{\circ} \mathrm{C}$ ) and partly episodically during active regeneration (at temperatures upstream of the DPF at 550-650 ${ }^{\circ} \mathrm{C}$ ) (e.g., Twigg 2007). Opposite to soot, the ash particles remain inside the DPF and accumulate within the filter. This leads to reduction of the effective filter volume and its operational lifetime. Moreover, ash particles alter the pressure drop sensitivity of the system to a certain degree (e.g., Sappok and Wong 2010).

It is obvious from the aforesaid, that the reduction of soot emissions through removal by oxidation is a very important issue influencing engine efficiency and environmental pollution. The response of soot to oxidation has been correlated with the internal structure (also referred to as nanostructure) of its primary particles (Su et al., 2004a, b; Müller et al. 2005, 2006). Soot nanostructure depends (among other factors) on the type of the fuel of origin (Boehman et al. 2005; Vander Wal et al. 2010). Previous studies have shown that the use of biofuel and/or mixing of bio- with diesel-fuel have an influence on the combustion products and a positive effect on passive regeneration (e.g., Boehman et al. 2005; Zabetta et al. 2006; Agarwal 2007; Lapuerta et al. 2008). Biofuel molecules contain oxygen atoms, which contribute to lower in-cylinder PM formation. Moreover, it has generally been suggested that biofuel produces soot, which is more prone to oxidation than diesel soot (Vander Wal et al. 2010; Song et al. 2007). Production of soot with nanostructures favorable to oxidation contributes to lower regeneration temperatures, which translates to better engine performance and lower fuel consumption. On the other hand, it was found that biofuel may produce more ash PM, which can not be chemically eliminated and gradually fills up the DPF at the expense of engine efficiency (e.g., Zabetta et al. 2006; Liati et al. 2011).

It is therefore evident that detailed knowledge of the nature, physical, as well as chemical properties of PM emissions related to the use of bio- versus diesel fuels is expected to contribute to the improvement of engine performance and optimization of the operational characteristics of DPF systems. While a number of studies have been devoted to the general characteristics of emissions produced during the combustion of diesel fuel, our knowledge on the detailed nature, morphology, and size of PM related to the use of biofuels is limited (e.g., Tsolakis et al. 2007; Wu et al. 2008 and references therein). Even less information is available on PM depositions in DPF operating with biofuels. A promising approach towards investigation of the nature, physical and chemical characteristics, distribution pattern, and amounts of biofuel-emitted PM is to examine the particles trapped in DPFs.

Within the framework of this work, PM depositions in three loaded DPFs from a small heavy duty engine operating on the test bench with different percentages of rapeseed methyl ester (RME), a commonly used biofuel in Europe (e.g., Nishi et al. 2004), are studied. The studies were carried out 'in situ' on the DPFs through targeted dissection and/or in samples extracted mechanically from different sites of the dissected DPFs. The aim of this investigation is to provide information on: (a) the nature and origin of the different particle types trapped in the DPFs, (b) the macroscopic characteristics of the PM deposits, such as deposition pattern, amount and relationships between the different types of PM, and (c) the microscopic characteristics of the different PM, such as morphology and structure, down to the nano-scale range. The latter point is especially important for primary soot particles, as their internal nanostructure can be correlated with their oxidative reactivity. The results of this study are expected to contribute to modeling and simulation efforts and can prove useful for improving aftertreatment strategies and engine 
performance. Moreover, they can contribute to a better understanding of the impact of diesel PM on the environment.

\section{Experimental}

Diesel particulate filters

The experiments were carried out on the test bench with three new silicon carbide DPFs with a conventional 'honey comb' structure operating with the same engine. The engine characteristics are summarised in Table 1. The DPFs have external dimensions of $300 \mathrm{~mm}$ (length) by $151 \mathrm{~mm}$ (diameter), a volume of $4.9 \mathrm{dm}^{3}$, and a total surface area of $3.4 \mathrm{~m}^{2}$. They include four segments cemented together, each segment comprising $2.0 \mathrm{~mm}$ by $2.0 \mathrm{~mm}$ large rectangular channels (100 cells per square inch) with a wall thickness of $0.45 \mathrm{~mm}$ and $48 \%$ porosity. The channels are alternately closed at their ends. These DPFs are catalytically coated with $\mathrm{V}_{2} \mathrm{O}_{5} / \mathrm{TiO}_{2}$. Note that the entire DPFs have been immersed into the coating medium during production.

The following fuels were used for the experiments: $100 \%$ RME (B100), $20 \%$ RME (B20) and $100 \%$ diesel fuel (B0), in combination with a new DPF for every fuel type. A silicon carbide, Pt-coated DOC with Al-coating was included upstream of the DPF.

The DPFs were soot loaded in a rectangular cycle (800-1,100 rpm; 0-500 Nm) to an identical back-

Table 1 Characteristics of the engine, on which the studied DPFs operated

\begin{tabular}{ll}
\hline Manufacturer & $\begin{array}{c}\text { Liebherr Machines Bulle S.A., } \\
\text { Bulle/Fribourg } \\
\text { Type }\end{array}$ \\
Cylinder volume & $6.36 \mathrm{~L}$ \\
Rated RPM & $2,000 \mathrm{~min}^{-1}$ \\
Rated power & $111 \mathrm{~kW}$ \\
Model & 4 Cylinder in line \\
Combustion process & Direct injection \\
Injection pump & Bosch unit pumps \\
Supercharging & Turbocharger with intercooling \\
Emission control & None (exhaust gas aftertreatment \\
& according to the requirements) \\
Development period & 2005 \\
\hline
\end{tabular}

pressure of $\Delta P \approx 100$ mbar. Due to the use of different fuel types producing different amounts of soot, the back-pressure was applied as a proxy for similar loading conditions. For B0 and B20, soot loading was performed in the same way: three soot loading procedures (B0: $2 \mathrm{~h}, 1 \mathrm{~h} \mathrm{25^{ \prime }}, 1 \mathrm{~h} \mathrm{40}$; B20:

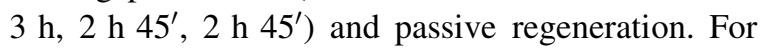
$\mathrm{B} 100$, a protracted soot loading procedure was undertaken $(27 \mathrm{~h})$, to arrive at an identical backpressure level of $\approx 100$ mbar. No acceleration of ash loading was undertaken. Regeneration was conducted by increasing the engine load (torque) in steps of $10 \mathrm{~min}$ at a constant engine speed of $1100 \mathrm{rpm}$. The exhaust temperature for the start of regeneration was around $220{ }^{\circ} \mathrm{C}$. Before initial use, the DPFs were shortly degreened for approximately half an hour. Finally, with each fuel type change, the tubes to the engine were cleaned.

In addition to the three DPFs, the DOC was also investigated for possible PM deposits or for any other information that would prove useful for understanding the nature of PM depositions in the DPF downstream of the DOC.

Analytical techniques

For the macroscopic examination of PM depositions, the DPFs were split into segments, which were in turn sectioned parallel and perpendicular to the flow direction. Part of the PM deposits in the DPFs were extracted mechanically from the inlet and/or outlet channels, while parts of them were investigated 'in situ', as deposited within the DPF channels.

The characterization of the PM deposition pattern was done on a macro-scale, as well as by optical microscopy under a simple stereomicroscope. For more detailed information, selected samples were prepared for scanning electron microscopy (SEM), in high vacuum, combined with an energy dispersive $\mathrm{X}$-ray system (EDX) for qualitative chemical analysis. For SEM imaging, a Hitachi S-4800 instrument at EMPA laboratories was used. Finally, data on the nanostructure of soot from the B100- and B0-DPFs were obtained by transmission electron microscopy (TEM) mainly in high resolution. The TEM instrument was a JEOL FS2200 with in column filter, at EMPA Laboratories. 


\section{Macroscopic and optical microscopic observations}

Soot

The DPFs have a characteristic greenish color, due to the $\mathrm{V}_{2} \mathrm{O}_{5} / \mathrm{TiO}_{2}$ catalytic coating material. Both the $\mathrm{B} 0$ and the B20-DPFs display extensive soot deposition all along the DPF length. Optical microscopic observations of DPF channels from the B0- and B20-DPF reveal that soot forms a relatively compact cake deposited solely on the inlet channels (Fig. 1a), a feature commonly observed with diesel DPFs (e.g., Song et al. 2007; Bensaid et al. 2009 and references therein).

The dissected B100-DPF, on the other hand, displays very little amounts of soot depositions (Fig. 1b). It is notable, however, that fine soot agglomerates fall out of the DPF under slight shaking. Fragments of a soot cake, several tens to hundreds of micrometers large, occur in minor amounts in some of the channels of this DPF. Based on the shape of the soot cake fragments, which corresponds to the negative form of a square-shaped channel, it is inferred that soot was detached from the channel wall at some stage of the DPF operation. Detachment of the soot cake from the channel wall during disassembly of the DPF can not be excluded, but even if this were the case, it would imply that it did not hold well on the walls, as with the B0- and B20-DPFs. An explanation regarding this issue is given below in the light of further investigations on the DPF PM deposits ("SEM imaging of ash deposits" section). Considering that soot acts as an additional filtration medium for emitted PM, the absence or temporary presence of a soot cake deposit on the B100-DPF may lead to reduction of its filtration efficiency. Freshly regenerated DPFs or DPFs without developed soot cake measured in our laboratory indeed show a filtration efficiency of around $90 \%$, opposite to $>99 \%$ of diesel DPFs with well-developed soot cake (Schreiber et al., 2007).

\section{Ash}

Abundant ash deposits are observed on the inlet surface of the B100-DPF (Fig. 2a). Ash is already recognizable macroscopically by its beige/orange color. It occurs on the surface of the channel walls and on the slightly protruding plugged surfaces of the outlet channels. In some cases, ash seems to have

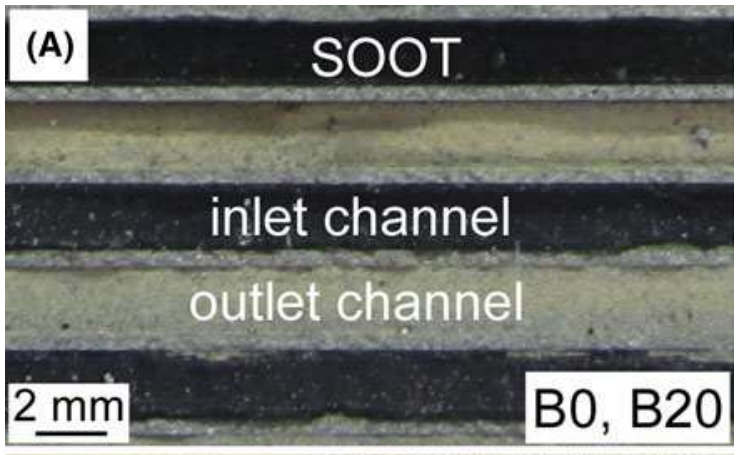

(B)

\section{inlet channel}

outlet channel

\section{$2 \mathrm{~mm}$}

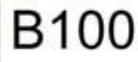

Fig. 1 Photographs of dissected segment pieces of DPFs parallel to the gas flow. a Abundant soot deposits in the B0DPF (identical to the B20-DPF). b No soot deposits are visible in the B100-DPF at this scale

penetrated locally through the interface between the channel wall and outlet channel plugs at the DPF inlet, on the first 2.3-2.7 $\mathrm{mm}$ of the ca. 4-mm long plugs of the outlet channels (Fig. 2b), as was confirmed by EDX analyses (see "SEM imaging of ash deposits" section).

Ash deposits are also observed on the first 0.8$1 \mathrm{~mm}$ of inlet channels at the inlet side of the B100DPF (Fig. 2B), then their amount diminishes abruptly toward the outlet and ash is found in form of dispersed aggregates all along the channel length of this DPF. Finally, ash depositions occur at the outflow side of some plugged inlet channel ends (Fig. 2C), where they locally block a maximum of ca. $15 \mathrm{~mm}$ of the ca. 300-mm long channels. Importantly, ash deposits in the B100-DPF have a quite loose structure, thus occupying a relatively large volume in the DPF channels. Note that ash deposits in diesel DPFs or, more generally, in DPFs with long operation time, are compact as a result of considerable soot production in the form of a soot cake, which compresses the ash deposited on the DPF walls (or on the plugged channel ends). The degree of ash compaction increases with an increasing number of regenerations. The limited 

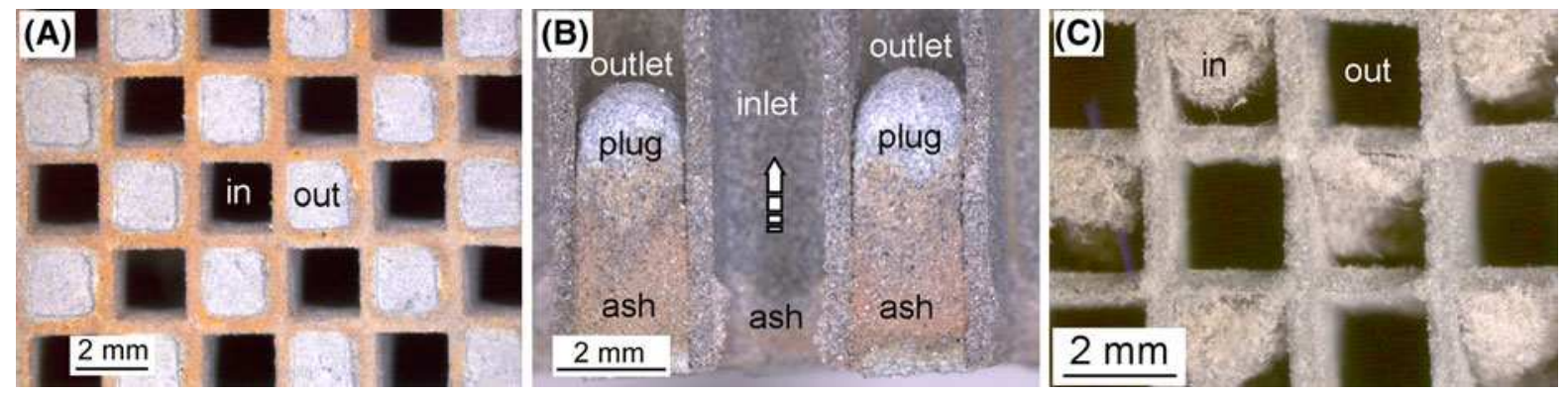

Fig. 2 Optical microphotographs of ash deposits (beige-orange color) in the B100-DPF. a Inlet surface of the DPF. b DPF segment parallel to the gas flow with ash depositions on the

operational time, in combination with the low soot production and the few regeneration processes undertaken in our experiments contribute to a very low degree of ash compaction.

Finally, considerable amounts of fibrous material, proven to originate mainly from the gasket applied at the DPF inlet and to a lesser extent from the intumescing mat enveloping the DPF-DOC assembly are also observed within the DPF, often together with ash (see "SEM imaging of ash deposits" section).

Ash depositions can not be distinguished macroscopically either in the B20- or in the B0-DPF implying that the biofuel must be a significant source of ash (see details "SEM imaging of ash deposits" section). Optical microscopic investigations allow the distinction of some ash agglomerates on the inlet surface of the B20- and, even less, on the B0-DPF.

\section{SEM imaging}

\section{SEM imaging of the DOC}

Three polished samples of the DOC embedded in epoxy were investigated: two from the inlet surface (one at the central part and one at the lateral part) and one from the middle central part of the $12 \mathrm{~cm}$-long DOC, between the inlet and outlet. SEM imaging from all three samples reveals the presence of abundant fissures in the coating layer (Fig. 3a). As a result of these fissures, Pt particles originally incorporated within the coating layer (Fig. 3b) can be locally detached and carried away with the exhaust stream toward the subsequent DPF. It can not be excluded that outlet channel plugs, inlet DPF side. c DPF segment perpendicular to the flow, at the outlet side, showing ash plugging in inlet channels

some of the Pt particles may reach the ambient air. Figure 3a depicts an example of two Pt particles that are candidates for escaping from the coating layer. In addition to $\mathrm{Pt}, 3-4-\mu \mathrm{m}$ large metallic fragments are also observed trapped in fissures of the coating layer (Fig. 3c). The fragments consist of $\mathrm{Fe}$ and $\mathrm{Ni}$ and probably derive from abraded engine parts. Finally, some ash particles consisting of $\mathrm{Ca}, \mathrm{S}, \mathrm{P}, \mathrm{Zn}, \mathrm{O}$, and minor amounts of $\mathrm{Fe}$ and $\mathrm{K}$ were detected (Fig. 3c).

Interestingly, $20-50 \mu \mathrm{m}$, more rarely down to $5-\mu \mathrm{m}$ large, round metallic pieces consisting of $\mathrm{Ti} \pm \mathrm{V}, \mathrm{Fe}$, and $\mathrm{Ni}$ occur within the main $\mathrm{SiC}$ body of the DOC (Fig. 3d). This mode of occurrence, in combination with their presence in all three samples examined, implies that these large metallic pieces belong rather to the original construction components of the DOC, and are differentiated from the metallic engine wear fragments by their shape, size, and chemical composition. It can not be excluded that local damage to the DOC may lead to liberation and further mechanical transport of such pieces or fragments of them.

\section{SEM imaging of soot depositions}

The compact soot cake observed with the stereomicroscope along the inlet channels of the B0- and B20DPF has been examined in detail on SEM images. SEM images reveal a more or less uniform soot layer deposition along all four walls of the square inlet channels, sometimes forming local bulges (Fig. 4a, c). Detailed measurements of the soot cake thickness reveal that in B0 it usually ranges between $\sim 200$ and $250 \mu \mathrm{m}$ and, in places, it may go down to 130 or up to $280 \mu \mathrm{m}$. Samples from the inlet, middle, and outlet 

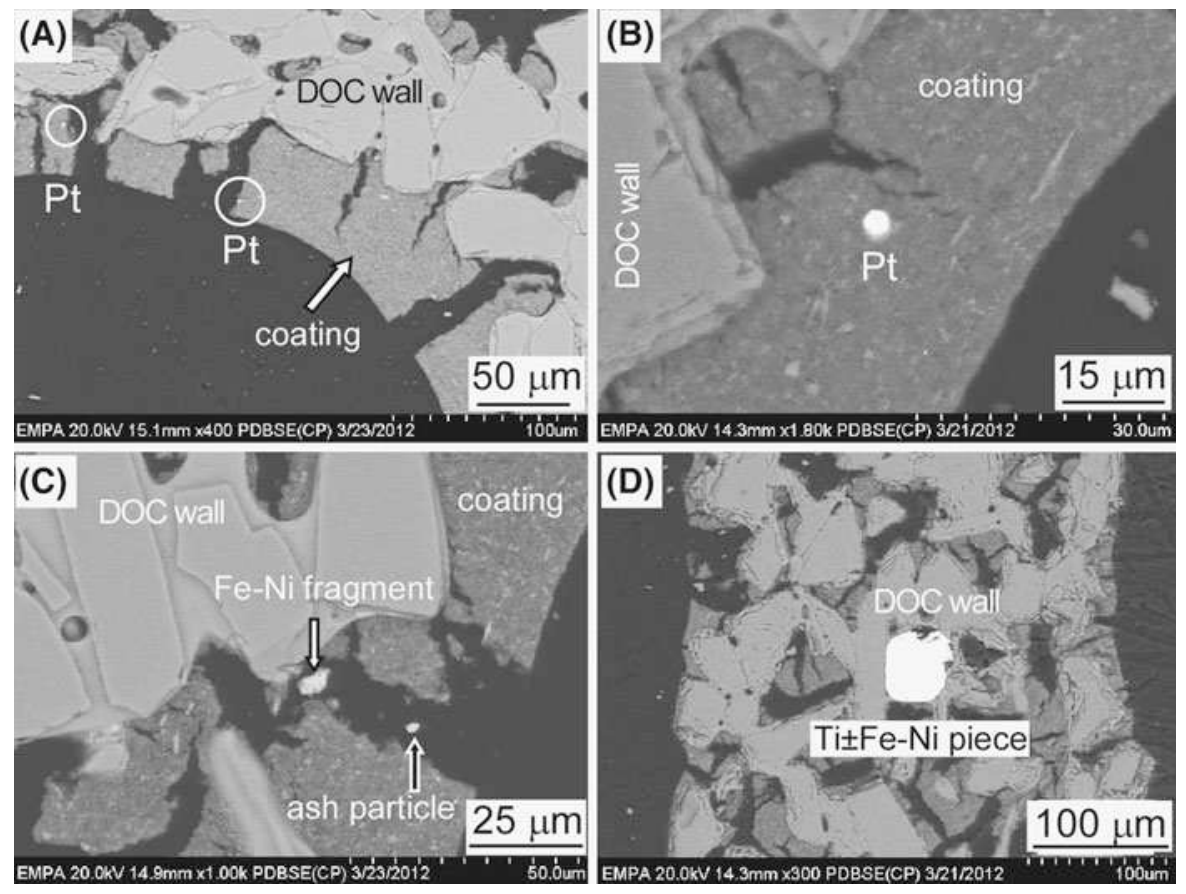

Fig. 3 SEM BSE images of polished samples from the DOC perpendicular to the gas flow. a Inlet side of the DOC with abundant fissures of the coating layer; encircled are Pt particles (bright) candidate for escaping from the coating layer. b $\mathrm{Pt}$

part of the B0-DPF reveal that the thickest soot cake occurs toward the inlet side, where it may locally reach 400-470 $\mu \mathrm{m}$ (Fig. 4b). Surprisingly, a significantly thinner soot cake (ca. 35-60 $\mu \mathrm{m}$, locally $90-\mu \mathrm{m}$ thick) has been observed in very few outlet channels close to the inlet side of this DPF (Fig. 4c, d). This is a rare case, as the high efficiency of such DPFs results in soot deposition in inlet channels only (e.g. Liati and Dimopoulos Eggenschwiler 2010 and references therein). As soot has not been found inside the wall of adjacent inlet channels, the presence of a thin soot cake in very few outlet channels of the B0-DPF can be attributed to some local 'leakage' of the corresponding inlet plugs, which is probably also responsible for the locally observed penetration of ash through the interface between outlet channel plugs and channel wall (see "Macroscopic and optical microscopic observations" and "Ash" sections).

In B20, the soot cake shows similar thickness as in B0, as well as the same tendency of the thickest parts occurring toward the inlet side. However, here, the inlet side soot cake is thinner than in B0, $300-\mu \mathrm{m}$ thick. particle within an intact part of the coating layer. c Metallic fragment $(\mathrm{Fe}-\mathrm{Ni})$ and ash particle in a fissure of the DOC coating layer. d Metallic piece ( $\mathrm{Ti}-\mathrm{Fe}-\mathrm{Ni}$ ) embedded within the DOC wall (middle part of the DOC, ca. $6 \mathrm{~cm}$ from inlet)

\section{SEM imaging of ash depositions}

For the SEM investigations of ash depositions, the inlet surface of the three DPFs, as well as inlet and outlet channels at different distances from the DPF inlet were studied. SEM imaging reveals that ash occurs in form of agglomerates, i.e., ash particles held loosely together. The agglomerates fall apart easily into smaller pieces, ending as aggregated (firmly held) particles, several micrometers large (Fig. 5a-c). Investigation of ash separates obtained from within the B100-DPF and examined on TEM grids reveal that the size of individual ash particles of the aggregates ranges, in their majority, between ca. 50-300 nm (Fig. 5d). Larger and smaller particles are rarer.

For the B100-DPF, qualitative EDX analyses of the ash reveal the presence of mainly $\mathrm{O}, \mathrm{Ca}, \mathrm{S}, \mathrm{P}$, and smaller amounts of $\mathrm{Mg}$ and $\mathrm{Zn}$, and in places $\mathrm{Fe}$. $\mathrm{Al}, \mathrm{K}$, and $\mathrm{Na}$ are also abundant, with $\mathrm{Al}$ and $\mathrm{K}$ being locally enriched. $\mathrm{Fe}$, with minor amounts of $\mathrm{Cr}, \mathrm{Ni}$, and occasionally $\mathrm{Mn}$ and traces of $\mathrm{Cu}$ are detected locally, either within ash agglomerates or in form of distinct fragments, a few micrometers large to tens of 

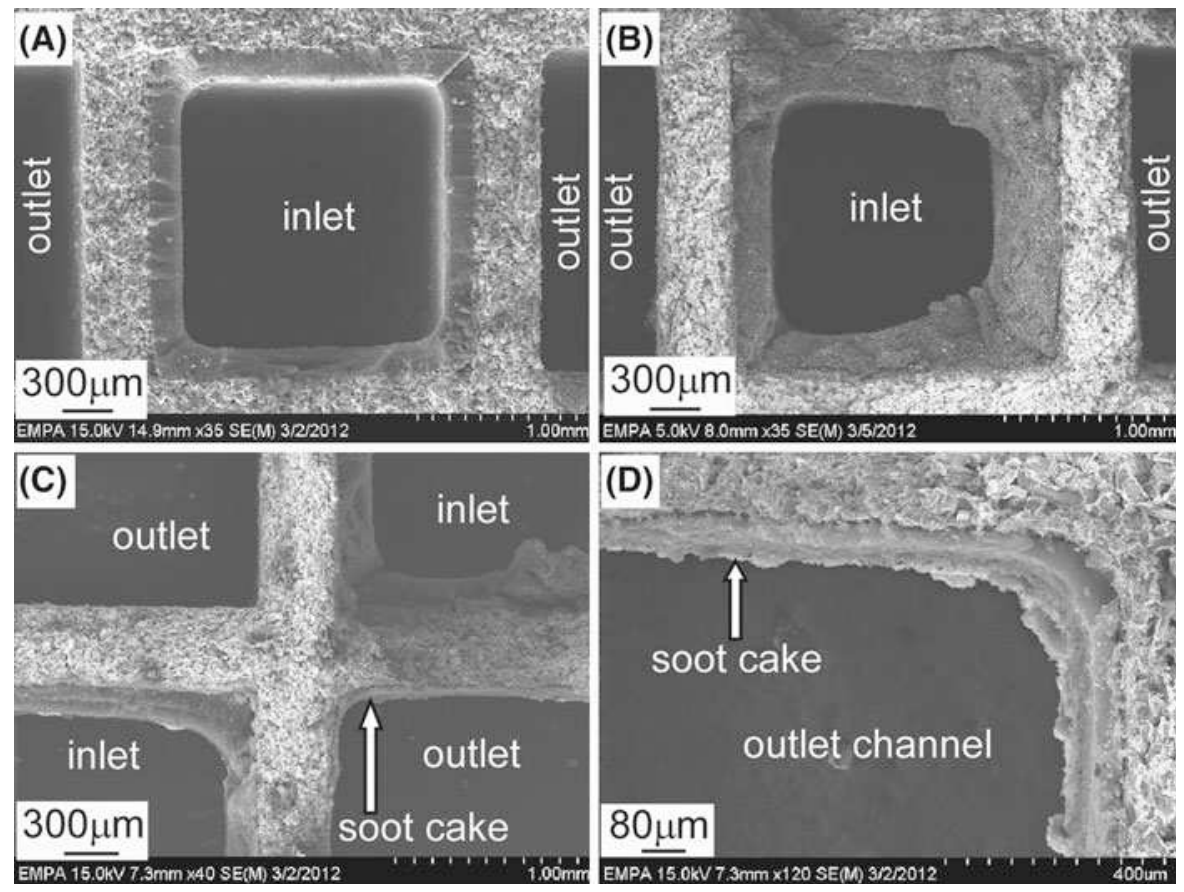

Fig. 4 SEM secondary electron (SE) images of DPF channels with soot depositions in different parts of the B0-, B20-, and B100-DPFs. a Middle part of the B0-DPF (identical to the B20DPF) with soot cake. b Inlet part of the B0-DPF with thicker

micrometers large (Fig. 5e, particles in circles). Smaller Fe-particles, down to a few tens of nanometers in size, occur locally. The origin of the above ash constituents is addressed at the end of this section, in the light of the ash chemistry of the B20- and B0DPFs. Finally, large amounts of $\mathrm{Si}, \mathrm{V}$, and $\mathrm{Ti}$ are always detected, as they are the main elements of the DPF (SiC) and catalytic coating material (Ti, V).

A very interesting finding of the ash study is the presence of Pt particles, ca. 50-400 nm large (Fig. 5a, e). Their composition was confirmed by EDX analyses. The Pt particles derive from the DOC placed upstream of the DPF. Pt is best distinguished on BSE images (Fig. 5e), where it appears much brighter, due to its significantly higher atomic weight, compared to that of the other elements participating in the chemical composition of the ash. This finding confirms the inference drawn from the SEM study of the DOC, that Pt particles can be detached from the coating layer (see "SEM imaging of the DOC" section). Most likely, Ptsintering in large particles took place inside the DPF after detachment from the DOC. The presence of $\mathrm{Pt}$ particles in ash deposits within DPFs has been soot cake. c Inlet part of the B0-DPF with a thick soot cake in inlet channels and a thin soot cake in an outlet channel. d An enlargement of the soot-bearing outlet channel shown in $\mathbf{c}$

described in previous studies (e.g., Liati et al. 2012). Detachment of Pt particles from the DOC may be a procedure contributing to its aging and needs to be followed up in detail.

For the B20-DPF, SEM imaging of the ash confirms the significantly lower ash deposits than for B100, identified both macroscopically, as well as with the optical microscope. Ash is best detected on the inlet surface of the DPF (Fig. 5b), as well as underneath the soot cake of inlet channels, between soot cake and coating layer (Fig. 5f). EDX analyses (rectangles in Fig. 5g) reveal mainly $\mathrm{O}, \mathrm{P}$, low amounts of $\mathrm{Ca}, \mathrm{Mg}$, $\mathrm{S}$, and traces of $\mathrm{Zn}$ and $\mathrm{Fe}$. $\mathrm{Fe}-\mathrm{Cr}-\mathrm{Ni}$ particles are present locally (Fig. 5f, g, black circles and black rectangles).

Ash in the B0-DPF occurs in traces. Most ash deposits are found on the inlet surface (Fig. 5c), while subordinate amounts occur underneath the soot cake, similar to B20. Regarding ash chemistry in this DPF, the most frequently detected element is $\mathrm{P}$, followed by $\mathrm{Ca}$, while $\mathrm{S}, \mathrm{Mg}, \mathrm{Zn}$, and $\mathrm{Fe}$ occur in traces. $\mathrm{Al}, \mathrm{Na}$, less $\mathrm{K}$, as well as $\mathrm{Fe}, \mathrm{Cr}$, and $\mathrm{Ni}$ are enriched locally (Fig. 5h). 

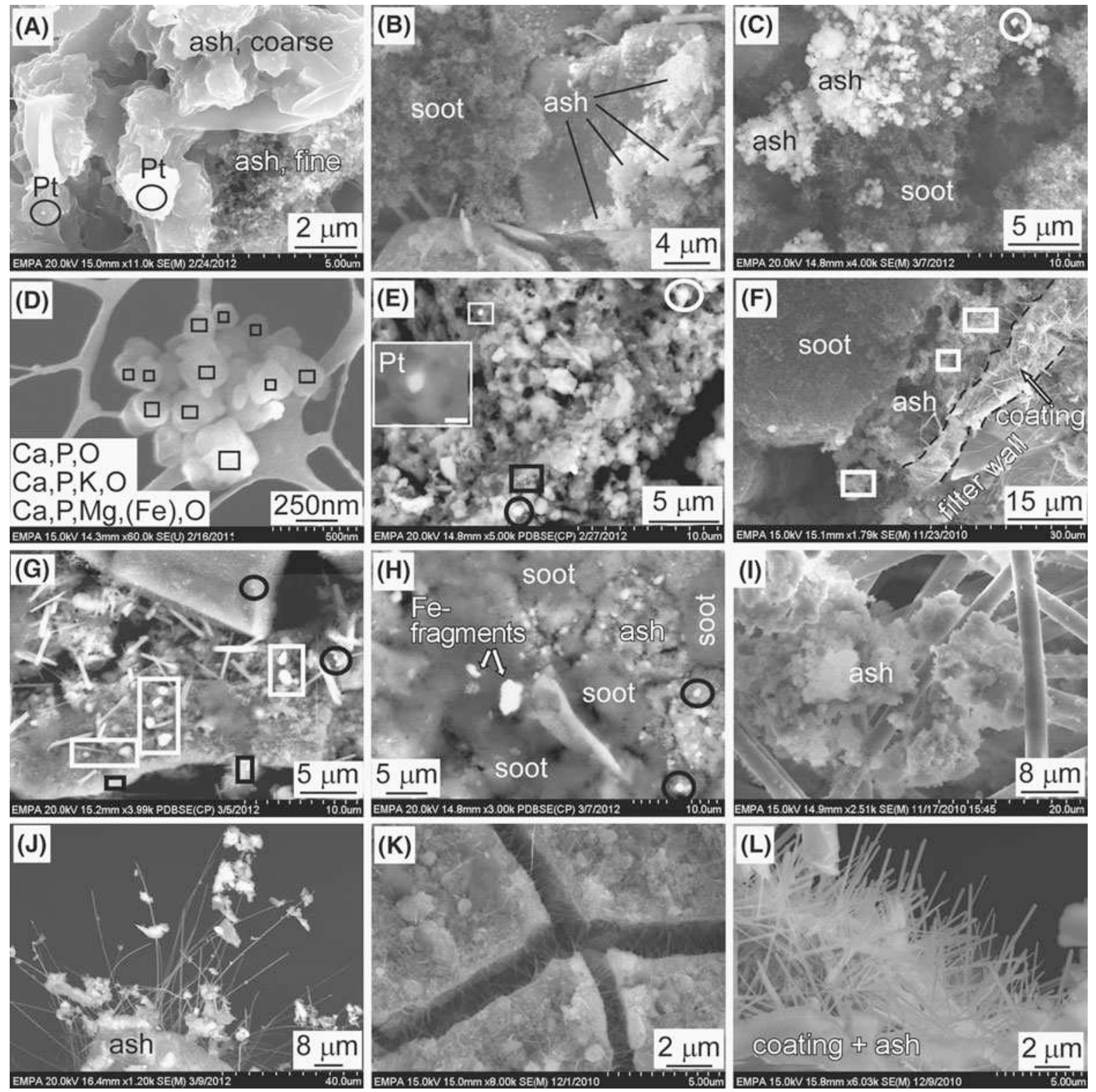

Fig. 5 SEM SE images (a-d, $\mathbf{f}, \mathbf{i}-\mathbf{l})$ and BSE images $(\mathbf{e}, \mathbf{g}, \mathbf{h})$ of ash PM. a Coarse and fine ash aggregates, locally with $\mathrm{Pt}$ particles. b, c Soot and ash in B20- and B0-DPFs; encircled in c is a metallic Fe-Ni-fragment. d Ash aggregate on a TEM grid; size and shape of the individual ash phases can be distinguished. e Ash deposits and Pt particle (white rectangle) enlarged in inset image (bar in the inset is $400 \mathrm{~nm}$ ); in circles are metallic $\mathrm{Fe}-\mathrm{Ni}$ fragments. $f$ Ash deposition between soot and coating layer in an inlet channel of the B20-DPF. Bright rods are V-O-crystals.

In order to trace the origin of the elements detected in the ash, it is important to mention that besides ash agglomerates and aggregates forming chemically g Ash aggregates (rectangles) and metallic fragments (circles). Black rectangles reveal more $\mathrm{Fe}$; randomly oriented rods are $\mathrm{V}-$ O-crystals. h Ash and soot deposits, as well as metallic Fe-Ni fragments; smaller metallic fragments are in circles. i Ash intermingled with Al-Si-fibers from the insulating mat. $\mathbf{j}$ Ash with $\mathrm{Ca}-\mathrm{Al}-\mathrm{Si}$-fibers of the gasket. $\mathbf{k}$ Fissures in the coating layer of the DPF filled with V-oxide long prismatic crystals. 1 An enlargement of $\mathbf{k}$. Rectangles in all images mark sites analyzed by EDX

during the high temperatures of combustion, some other material is found intermingled with ash. This material was transported mechanically within the 
DPFs with the exhaust stream and includes: (1) metallic phases of $\mathrm{Fe}-\mathrm{Cr}-\mathrm{Ni} \pm \mathrm{Mn} \pm \mathrm{Cu}$ mainly abraded from engine parts. The metallic phases, already mentioned above, are either micrometer-large fragments (Fig. 5h) or a few hundreds, down to tens of nanometers large particles (Fig. 5e, g). (2) Fibers distinguished into two types based on their size and chemical composition: (a) ca. $10-\mu \mathrm{m}$ thick and several micrometers long $\mathrm{Ca}-\mathrm{Al}-\mathrm{Si}-\mathrm{O}-$-fibers, deriving from an intumescing mat used as insulation medium around the DOC-DPF assembly (Fig. 5i) and (b) 100-200-nm thick and up to several micrometers long $\mathrm{Al}-\mathrm{Si}-\mathrm{O}-$ fibers deriving from a gasket placed at the outer part of the inlet DPF surface (Fig. 5j). It is noted that the origin of fibers within the ash deposits was confirmed by sampling and analyzing material from the intumescing mat and the gasket, both for their size and chemical composition.

It is also of interest to note the widespread occurrence of minute, long prismatic crystals in all three DPFs, in both inlet and outlet channels, as well as inlet and outlet surfaces. These crystals, which are $\sim 10-100 \mathrm{~nm}$ wide and up to a couple of micrometers long, consist of V-oxide, as determined by EDX analyses on isolated crystals with both SEM and TEM. They occur mainly within the coating layer, often sticking out of the DPF channel walls and/or growing perpendicular to the surface of fissures within the coating layer (Fig. 5k, 1). The latter mode of occurrence in the fissures indicates that at least part of these $\mathrm{V}$-oxide nanocrystals are not primary, but rather form newly during DPF operation. If detached from the DPF walls they at least partially reach the ambient air, but no measurements were performed during this study. Note that their size is within the breathable range.

Element mapping of ash aggregates deposited on the inlet surface of the B100-DPF reveals that the most frequent ash compounds are $\mathrm{Ca}-\mathrm{S}-\mathrm{O}$ phases, as well as $\mathrm{Ca} \pm \mathrm{P} \pm \mathrm{Mg} \pm \mathrm{K}$-O-bearing phases, while $\mathrm{K}$, $\mathrm{Al}$, and lower amounts of $\mathrm{Na}$ are enriched locally to form $\mathrm{Al}-\mathrm{K} \pm \mathrm{Na}$-phases (Fig. 6). Na-bearing phases are subordinate. In element maps of B20-ash aggregates, the ubiquity of $\mathrm{Ti}$ and $\mathrm{V}$ and the frequent occurrence of $\mathrm{K}, \mathrm{Na}$, and $\mathrm{Al}$ cover up the significantly subordinate $\mathrm{Ca}-\mathrm{P}-\mathrm{Mg}-\mathrm{Zn}-\mathrm{O}-\mathrm{S}$-compounds. Hence, element maps from the B20 ash are not presented here, as they did not prove as revealing as for B100 ash. It can, however, be noted that local enrichment of $\mathrm{Ca}$, usually in form of $\mathrm{CaO}, \mathrm{Ca}-\mathrm{P}-\mathrm{O}$, and more rarely $\mathrm{Ca}-$ $\mathrm{S}-\mathrm{O}$ compounds was observed during element mapping attempts. Element maps of B0 ash are not presented either, for the same reason as for the B20 ash.

A comparison of the ash characteristics in the three DPFs studied reveals that not only is the amount of ash deposits highest in the B100-DPF, but also that its chemical composition can be differentiated depending on the fuel type used. Thus, the ash in the B100-DPF is dominated by $\mathrm{Ca}-\mathrm{P} \pm \mathrm{S}-\mathrm{O}$ phases with or without $\mathrm{Mg}, \mathrm{K}, \mathrm{Fe}$. The percentage of such phases is much lower in the B20-DPF, and even lower in B0. Instead, in $\mathrm{B} 20$ and $\mathrm{B} 0, \mathrm{Ca}$ is rather combined with either $\mathrm{O}$ alone or with $\mathrm{P} \pm \mathrm{Mg}$ to form $\mathrm{Ca} \pm \mathrm{P} \pm \mathrm{Mg}$-oxides, as $\mathrm{S}$ occurs in low amounts. These observations are reproducible in all samples studied.

A chemical analysis of the lubricating oil and of the B100 fuel with respect to ash elements is given in Table 2 (analyzing method: inductively coupled plasma-optical emission spectrometry, ICP-OES). A direct estimate of ash levels in the DPF based on the ash element contents of the ash-producing media is generally avoided. Such calculations over-estimate the quantity of ash in DPFs, most likely because of, e.g., lubricant volatility and deviations in assumed consumption rates, or because a substantial part of the ash is retained on surfaces inside the engine and exhaust systems (Britton et al. 2004; Watson 2010 and references therein). However, in order to emphasize here the contribution of the biofuel to ash production, $\mathrm{Ca}$ is selected as an example for the computation of biofuel- and oil-produced ash proportions. Taking the Ca contents shown in Table 2 into account, the running time of the engine $(27 \mathrm{~h}$ for $\mathrm{B} 100)$ and assuming a fuel (RME) consumption rate of $300 \mathrm{~g} / \mathrm{kWh}$ and a lubricating oil consumption rate of $0.5 \mathrm{~g} / \mathrm{kWh}$ at an engine load of $20 \mathrm{~kW}$ (as average values), the resulting amount of $\mathrm{Ca}$-ash derived from the biofuel is $810 \mathrm{mg}$ versus $710 \mathrm{mg}$ from the lube oil. This result, although deviating from the real mass of Ca-ash accumulated in the DPF, clearly confirms the significant contribution of the biofuel to ash production (Fig. 7).

The considerably higher amount of ash in the B100DPF may be responsible for the detachment of the thin soot cake from the channel walls. Note that in common diesel DPFs, there is usually no soot cake detachment, despite high ash levels at the filter walls, probably 

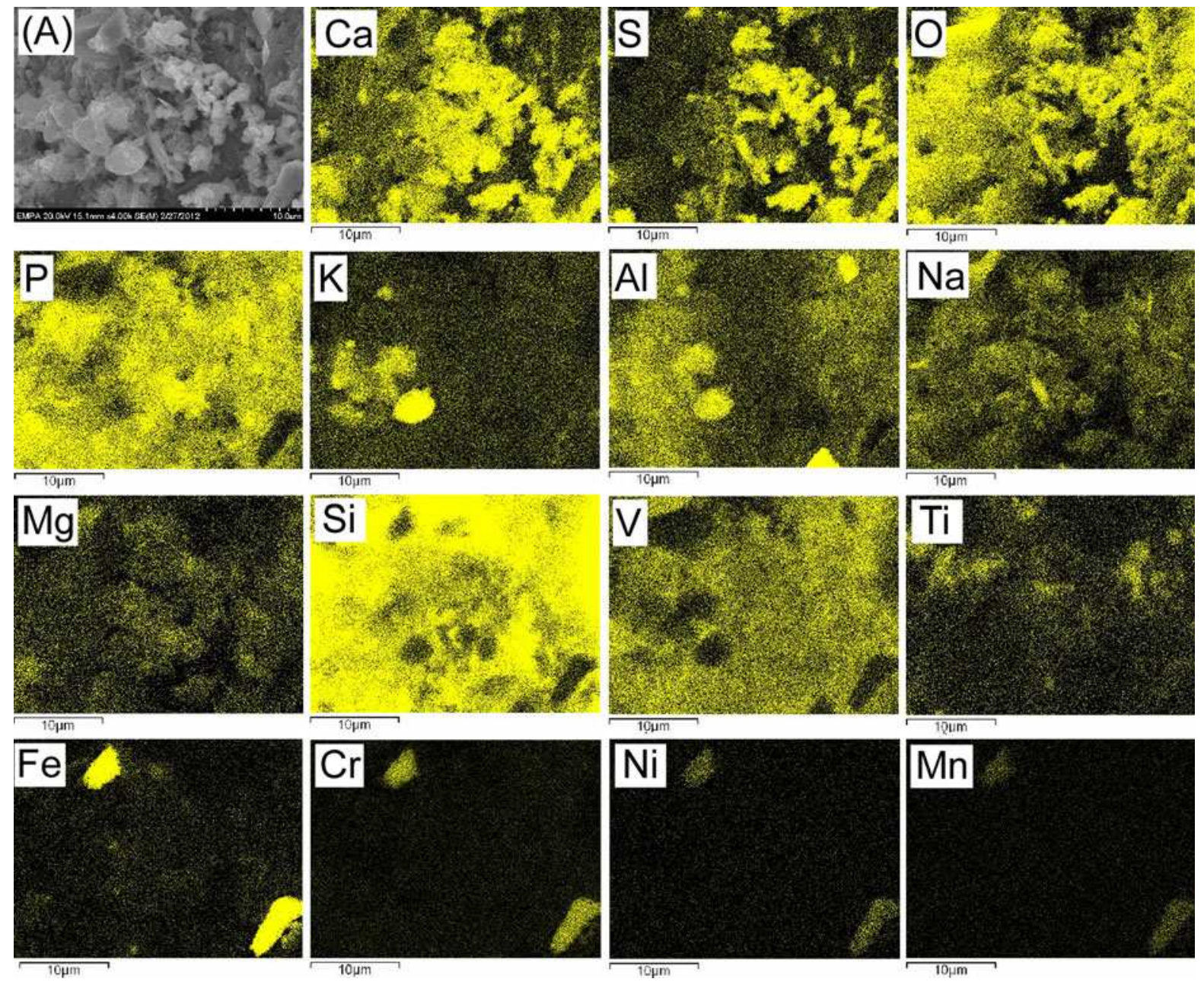

Fig. 6 a SEM SE image of an ash aggregate and element maps of this aggregate, as obtained by EDX analysis

because ash in those DPFs is quite compact, opposite to the ash observed in the B100-DPF studied here, which is very loose (see above). The lack of a soot cake on the DPF walls may contribute to reduction of the filtering efficiency of the DPF, as soot constitutes an additional filtering agent for the continuously incoming PM.

\section{HRTEM imaging}

It is generally accepted that diesel soot forms chainlike agglomerates composed of nearly spherical primary particles, usually a few tens of nanometers large. Based on a series of HRTEM studies (e.g. Boehman et al. 2005; Vander Wal et al. 2004; Song et al. 2006; Hays and Vander Wal 2007), the internal
Table 2 Chemical composition of the RME-biofuel and the lubricating oil used for the experiments of the present study

\begin{tabular}{lll}
\hline Element & B100-fuel $(\mathrm{mg} / \mathrm{kg})$ & Lubricating oil $(\mathrm{mg} / \mathrm{kg})$ \\
\hline $\mathrm{Ca}$ & 5 & 2,630 \\
$\mathrm{P}$ & $<4$ & 1,110 \\
$\mathrm{~S}$ & 5 & 3,360 \\
$\mathrm{Mg}$ & 0.5 & $<10$ \\
$\mathrm{~K}$ & 3 & - \\
$\mathrm{Na}$ & 0.5 & - \\
$\mathrm{Zn}$ & - & 1,200 \\
\hline
\end{tabular}

structure of soot is characterized by the presence of graphene layers and, to some extent, polyaromatic hydrocarbons (PAH) and heteroatoms (atoms other than carbon), most commonly hydrogen. The length, 


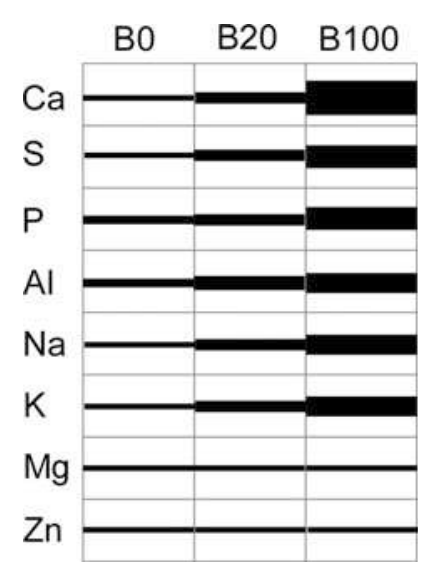

Fig. 7 Sketch displaying approximately the relative abundances of ash elements in the B0-, B20-, and B100-DPFs, based on EDX analysis. The bars have no units

degree of curvature, separation distance, and degree of crystalline order of the graphene layers (further on referred to also as lamellae) are four critical characteristics of the internal soot nanostructure associated with its oxidative reactivity (e.g., Knauer et al. 2009; Yehliu et al. 2011 and references therein). Short as well as curved graphenes are more prone to oxidation than are longer or planar ones, as they have more edge sites, which can be more easily accessible to oxygen than bonds located inside the basal plane of the lamellae. As for the degree of crystalline order of soot (also referred to as crystallinity or graphitization degree), it is determined by the constant separation distance of the graphene lamellae. The closer to graphite the separation distance, the more difficult it is to oxidize. Graphene lamellae of diesel soot particles display variations in the degree of ordering forming packages (crystallites) with locally regular arrangements, but lacking periodicity. Moreover, graphene lamellae in diesel soot particles may form well curved, fullerene-like structures (closed, tube-like graphenes with a nearly circular or ellipsoidal shape, e.g., Cataldo 2002; Su et al. 2004a), which are more easily oxidized than equally long planar graphenes. The innermost part of soot particles has been interpreted as more or less amorphous, and therefore most reactive.

Finally, the oxidative reactivity of soot depends on the size of the particles, the smaller particles being oxidized more easily than the larger ones (due to a higher surface to volume ratio).

Variations in the above-described structural pattern of soot primary particles depend mainly on the composition of the initial fuel, the engine operating conditions, the nature of gases in the exhaust stream, and the ambient temperature (e.g., Song et al. 2006; Vander Wal et al. 2010; Kim and Wang 2007). Primary soot particles can modify their morphological and internal structural characteristics during postformation thermal treatment and oxidation (Song et al. 2007).

HRTEM imaging can provide a direct measure of the graphene length, curvature, periodicity, separation distance, and orientation of the graphene layers at any particular depth in the spherical particle, as determined by the imaging focal plane. It needs to be kept in mind that TEM images are two-dimensional projections of three-dimensional structures. Thus, the imaging characteristics obtained by HRTEM for the innermost parts of the soot spherical particles (highest focus depth) are considered less detailed, and hence less straightforward to interpret compared to those of more outer parts. There is, therefore, some degree of uncertainty concerning the interpretation of the graphene layers (dis)order for the central, i.e., innermost part of the particles.

\section{(HR)TEM imaging of B100 and B0 soot}

Samples of soot for (HR)TEM studies were obtained from the soot cake deposited in the B100- and B0DPFs. Several locations of the TEM grids were investigated for the detailed study of soot. For the determination of soot particle size distribution, overview images of agglomerates were taken at $50 \mathrm{k} \times$ and $100 \mathrm{k} \times$ magnifications. The biofuel-derived soot primary particles show slightly lower sizes than those derived from diesel (B100: 190 measurements; B0: 180 measurements). The size distribution of the two soot types is shown in the histogram of Fig. 8. The somewhat lower mean particle sizes of biofuel soot indicate a slightly higher oxidative reactivity compared to diesel soot, as far as the particle size is concerned.

High resolution images at $400 \mathrm{k} \times$ and $600 \mathrm{k} \times$ magnifications were used to decipher the internal soot particle structure. Due to the strong coalescence tendency of soot, it was impossible to localize an entire soot particle that did not at least partly overlap with others. The best imaged soot particles showing the least overlap with neighboring ones are presented in Fig. 9. HRTEM images in their printed form are 


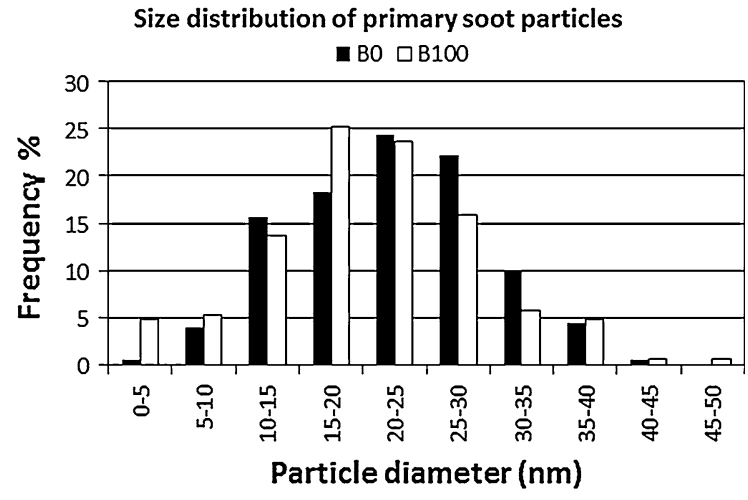

Fig. 8 Size distribution of primary soot particles for the B100 (190 measurements) and B0 (180 measurements) fuel showing the prevalence of smaller particles in the soot of B 100

often a little fuzzy, thus not allowing the reader to follow up the morphological characteristics of the internal particle structure, with clarity. This disadvantage has been eliminated here by graphically reproducing precise sketches, one to one, directly from the HRTEM images (Fig. 9).

Evaluation of the high resolution images (Fig. 9) reveals some common characteristics of the B100 and B0 soot. The primary soot particles of both fuel types consist of two different parts with contrasting degrees of structural order: (a) an inner part with unsystematically oriented graphene layers, as well as disordered atomic arrangements not forming distinct graphene lamellae (grayish appearance on images). This part of the particle part is commonly referred to as the 'amorphous core'; (b) an outer part, which constitutes the main particle volume, composed of numerous distinct graphene lamellae with very low periodicity. Amorphous areas crosscut the graphene lamellae (gray areas in Fig. 9). It is of interest to note that for both fuels, the core makes up ca. $1 / 3$ to $1 / 4$ of the particle volume, irrespective of the particle size. A soot particle may contain several cores, implying that some of the cores failed to develop separately into single particles. The multiple nuclei mode of occurrence indicates that such particles probably formed in an early phase of soot formation through nuclei coalescence and evolved further as a single particle.

\section{B100 soot particles (Fig. 9a, b)}

The graphene lamellae of the B100 soot particles show a series of defects. They depict local deformational features, such as twisting, tilting, and slight bending. Twisting may result locally in the formation of $180^{\circ}$ curved, hairpin-like lamellae, while slight bending produces undulations. Cross-links between adjacent lamellae and misalignments are locally visible. Considerably curved graphenes described elsewhere for diesel particles (e.g. Zhu et al. 2004) are rarely found, while fullerene-like graphene formations are completely lacking. It is reminded that curvature in graphene sheets results from the interference of carbon pentagons (C5) or heptagons (C7) in the hexagonal graphene structure, causing a positive or negative curvature, respectively (see e.g., Cataldo 2002). Curvature may also be the result of a local straining effect. The very low degree of graphene curvature in the B100 soot tends to favor the view of local straining rather than interference of non-hexagonal carbon structures. The spherical soot particles grew through the continuous attachment of small, more or less planar, slightly deformed graphene sheets on the surface of a primary, more or less amorphous spherical core.

Packages of well-ordered graphenes (crystallites) occur rarely and include usually 3-4, in one case 7 alternating lamellae. The inter-lamellar distance ranges between 0.373 and $0.381 \mathrm{~nm}$, thus being significantly larger than the $0.335 \mathrm{~nm}$ graphene plane distance in graphite.

All of the above-described characteristics are indicative of relatively highly disordered and hence easily oxidized soot particles.

\section{BO soot particles (Fig. 9c-f)}

The B0 soot particles examined share, to a large extent, the same characteristics as those from B100, as far as the defects of graphene lamellae and the configuration of the spherical soot particles are concerned, but are differentiated on the following characteristics: (a) the higher percentage of crystallites, as well as the higher number of well-ordered graphene lamellae in the crystallites. The crystallites include commonly 3-4, and less commonly, 5-6 lamellae. In one case, a graphene package was found, which includes 10 alternating lamellae with an interlamellar distance of $0.365 \mathrm{~nm}$. (b) the inter-lamellar distances are shorter than in B100 soot (0.365$0.372 \mathrm{~nm}$ ), and therefore closer to the $0.335-\mathrm{nm}$ graphene plane distance of graphite. Both of these 


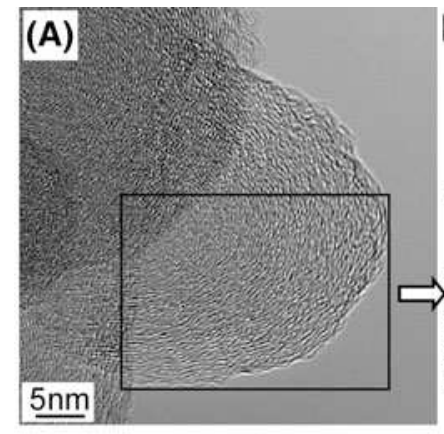

B100
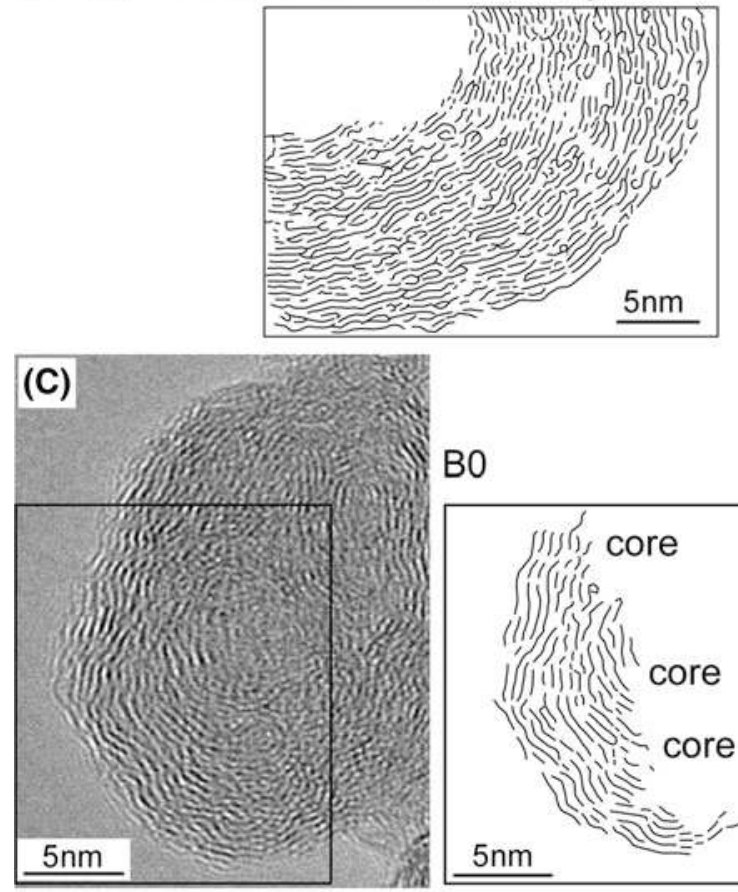

\section{B0}

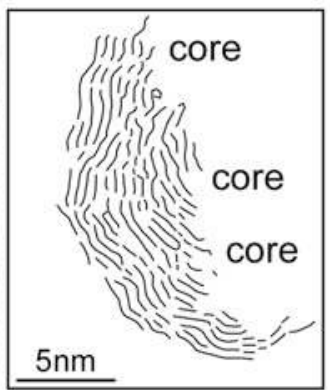

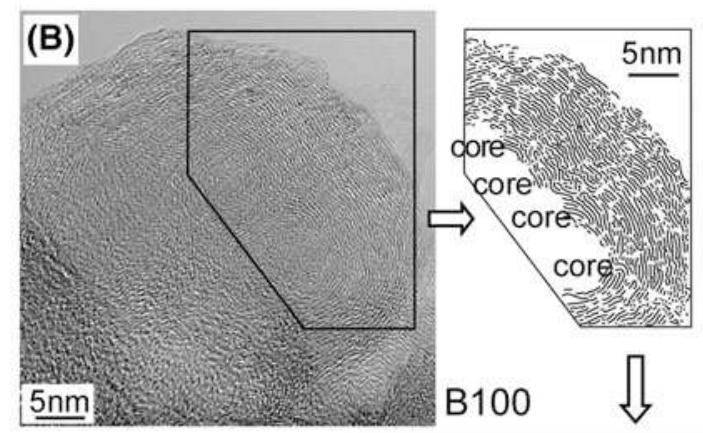
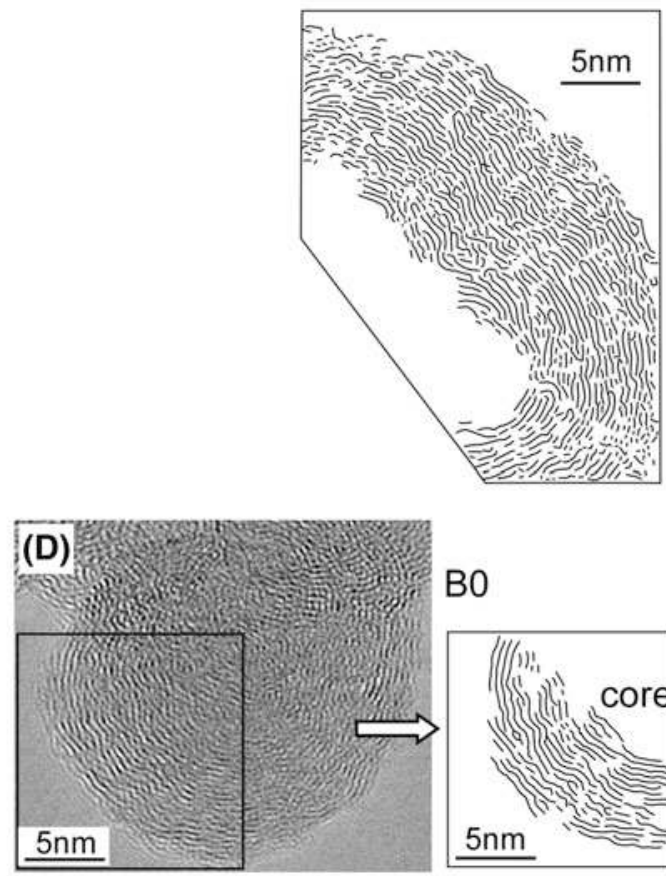

BO

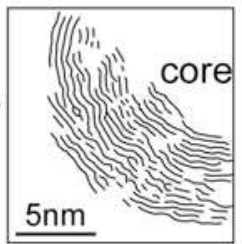

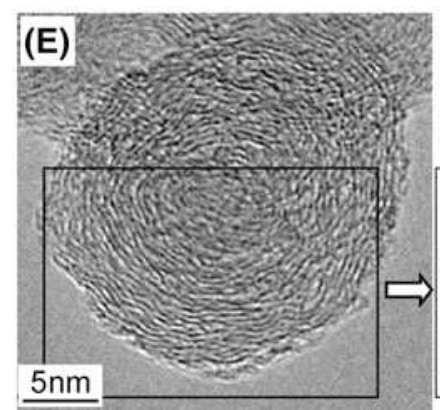

\section{B0}

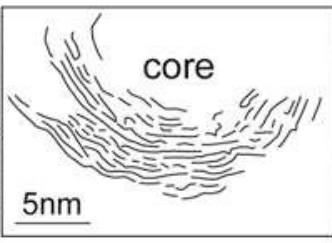

Fig. 9 HRTEM images of B100 (a, b) and B0 (c-f) soot and sketches, graphically reproduced 1:1 from the corresponding images to clearly depict the morphology of the graphene sheets in the soot particles. The thickness of the lines is not to scale, i.e., does not correspond to the thickness of the graphene sheets. The areas across the graphenes left blank on the sketches correspond

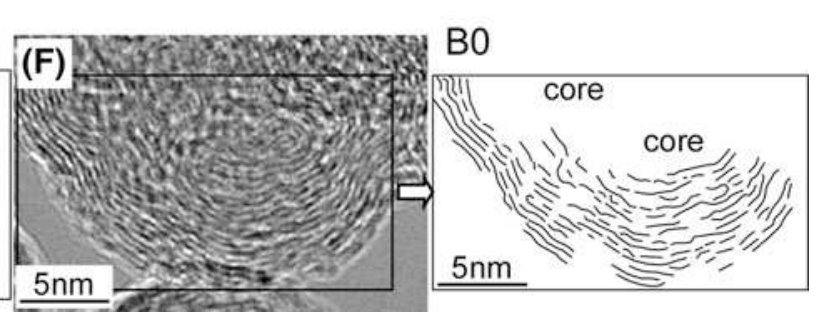

either to amorphous parts (gray on the images) or the shape of the graphene sheets was unclear to reproduce. For $\mathbf{a}$ and $\mathbf{b}$, a magnification of the sketches is given for clearer to-scale comparison with the B0 soot sketches. Note that for $\mathbf{c}$, the scale is a little larger 
distinctive features indicate a lower oxidative reactivity of the B0 compared to B100 soot.

Comparison of graphene lamellae length and curvature between $\mathrm{B} 100$ and $\mathrm{B} 0$ soot

For a direct comparison of biofuel- and diesel-derived soot, quantification of the length and degree of graphene curvature is necessary. Previous work dealing with the quantification of carbon nanostructures from HRTEM images in terms of graphene lamellae length and curvature is based on a series of operations of digital image processing and an image analysis algorithm (Müller et al. 2007; Schuster et al. 2011; Yehliu et al. 2011 and references therein).

Within the framework of the present paper, a similar yet simpler method has been applied, which does not involve any image processing analysis in terms of adjusting parameters of the HRTEM photographs themselves (e.g. brightness, contrast, color scales), and is sufficiently accurate for the purpose of the present investigation. The present method is based on an algorithm developed on the basis of sketches derived directly from the HRTEM images for B100 (two particles) and B0 soot (three particles) (Fig. 9). The length of the graphene lamellae was measured from these sketches and then the curvature was computed by means of a self-written program. The graphene lamellae were digitized using simple freeware software, which supplied the points of the lamellae-pixels in a given coordinate system. The coordinates were subsequently processed and a polynomial of sixth degree was fitted to the data. This polynomial was used to determine: (a) lamellae length and (b) lamellae curvature. Based on these measurements, the curvature was iteratively calculated to equate to that of a circle arc, where the arc length $(l)$ is the length of the lamella and the chord length $(c)$ is the distance between the lamella endpoints (Fig. 10). The derived arc curvature is then inverse to the circle radius. Thus, a curvature of zero (or infinite radius) corresponds to straight lamella, and a larger curvature (smaller radius) corresponds to a more convoluted line. For a more accurate approach in comparing B100 and B0 graphene lamellae characteristics, the graphene length has been normalized to the particle size (division by the particle radius). The derived curvature has been corrected to account for particle size by multiplication with the particle radius.
The results of the measurements and calculations for the B100 and B0 soot are graphically illustrated in Fig. 11. B100 soot shows a significantly higher percentage of shorter graphene lamellae compared to B0 soot (Fig. 11a). Differences between B100 and B0 graphene length also exist when comparing the structured inner and outer part of the same particle (the unstructured core is excluded for this comparison). While both the B100 and B0 particles exhibit a larger portion of shorter lamellae in the inner part, the difference in lamellae length between inner and outer part is more pronounced for the B0 soot (Fig. 11b, c). The latter observation implies that in contrast to the diesel soot, the biofuel-derived soot remains reactive when the particle grows large, as far as the graphene length is concerned. The above features become even more evident when the lengths are normalized to account for the particle size (Fig. 11d).

As for the curvature, the B100 soot particles exhibit a considerably higher proportion of curved graphene lamellae than the B0 ones (Fig. 12a). The inner part of the particles of both soot types contains more curved lamellae than the outer part (Fig. 12b, c). Interestingly, the proportion of curved lamellae between inner and outer particle part is higher in the B0 particles than in those of the B100. This inference is in line with the above-described observation that the biofuel-derived soot remains well reactive during particle growth whereas the diesel soot becomes more crystalline. As was the case for the graphene length, the abovedescribed features concerning graphene curvature become stronger when normalized to the particle size (Fig. 12d).

\section{Implications of the HRTEM results}

The present results of HRTEM imaging of primary soot particles derived from biofuel and diesel reveals that both soot types show relatively random arrangement of short-range and little curved graphene lamellae. Image processing and detailed study of the nanostructural characteristics of the soot primary particles reveals that biofuel-derived soot is more prone to oxidation than diesel soot, on the basis of: (a) larger mean graphene lamella separation distance, (b) less numerous and thinner crystallites, (c) smaller graphene lamellae length, and (d) higher graphene lamellae curvature. The longer duration of the regeneration procedure applied for diesel soot may be a 


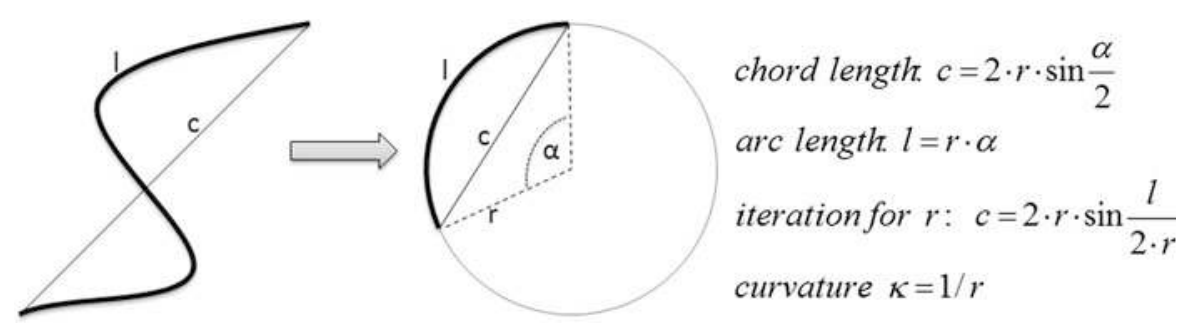

Fig. 10 Depiction of the method used to arrive at a quantification of the curvature for graphene lamellae

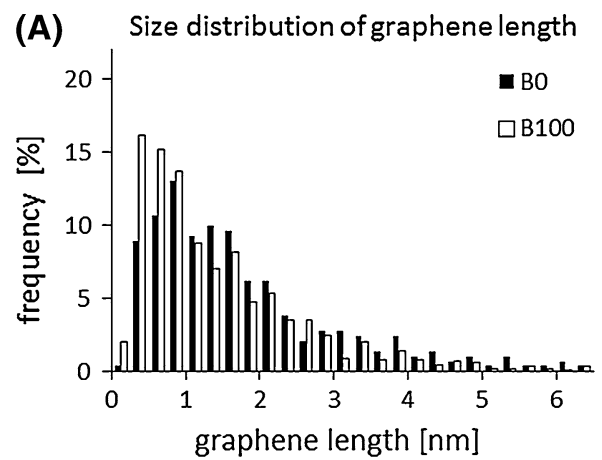

(C) Size distribution of graphene length

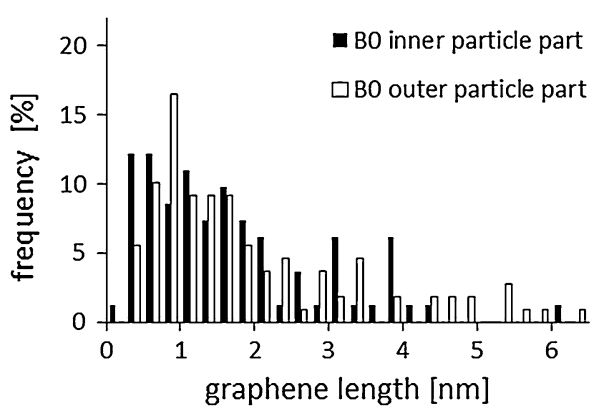

Fig. 11 Histograms of graphene length for the B100 and B0 soot

factor favoring the formation of more ordered lattice planes of stacked graphene layers for the remaining soot in the B0-DPF.

Regarding the size of the soot primary particles, the results of this study indicate rather small differences in the particle sizes between the two soot types. In the literature, both significant and negligible differences between diesel and biofuel soot particle sizes are reported (Jung et al. 2006; Lapuerta et al. 2008). It can thus be suggested that it is rather uncertain to predict differences in soot reactivity between biofuel and diesel soot solely on the basis of the primary particle size. It is also difficult to decide which one of the above soot nanostructural characteristics (a-d) is
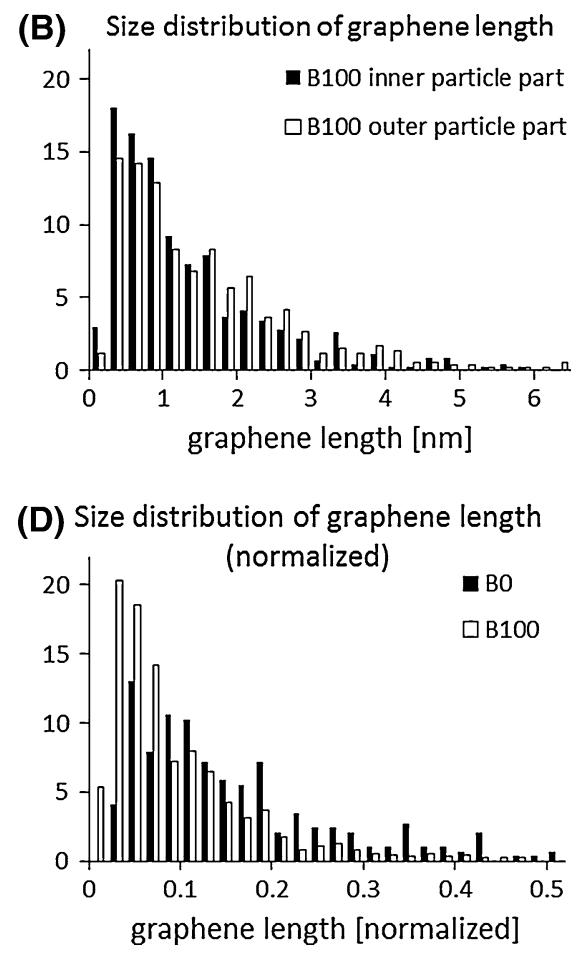

weighing more than the other, but the overall effect of the differences described above favors easier oxidation of the biofuel soot nanostructural features, in agreement with previous studies (Yezerets et al. 2003; Song et al. 2006; Knothe 2008; Vander Wal et al. 2010; Lamharess et al. 2011).

The difference in oxidative behavior between biodiesel- and diesel-derived soot is, to a significant extent, due to the composition of the initial fuel, which leads to the formation of different soot-producing primary species derived by fuel decomposition (e.g., Vander Wal et al. 2004; Lapuerta et al. 2008). Thus, the oxygen content of the biodiesel molecule enables more complete combustion, even in areas of the 
Fig. 12 Histograms of graphene curvature for the $\mathrm{B} 100$ and $\mathrm{B} 0$ soot

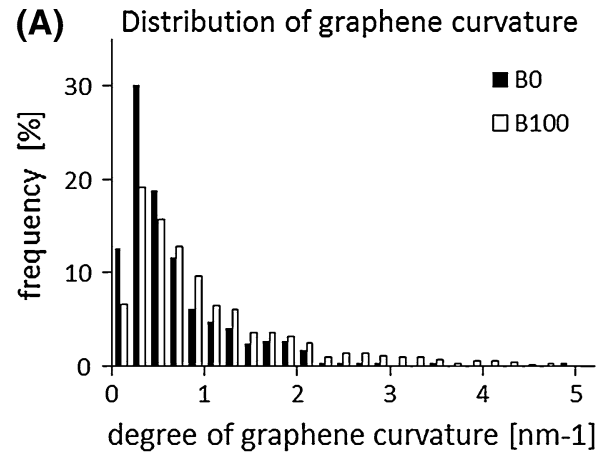

(B) Distribution of graphene curvature
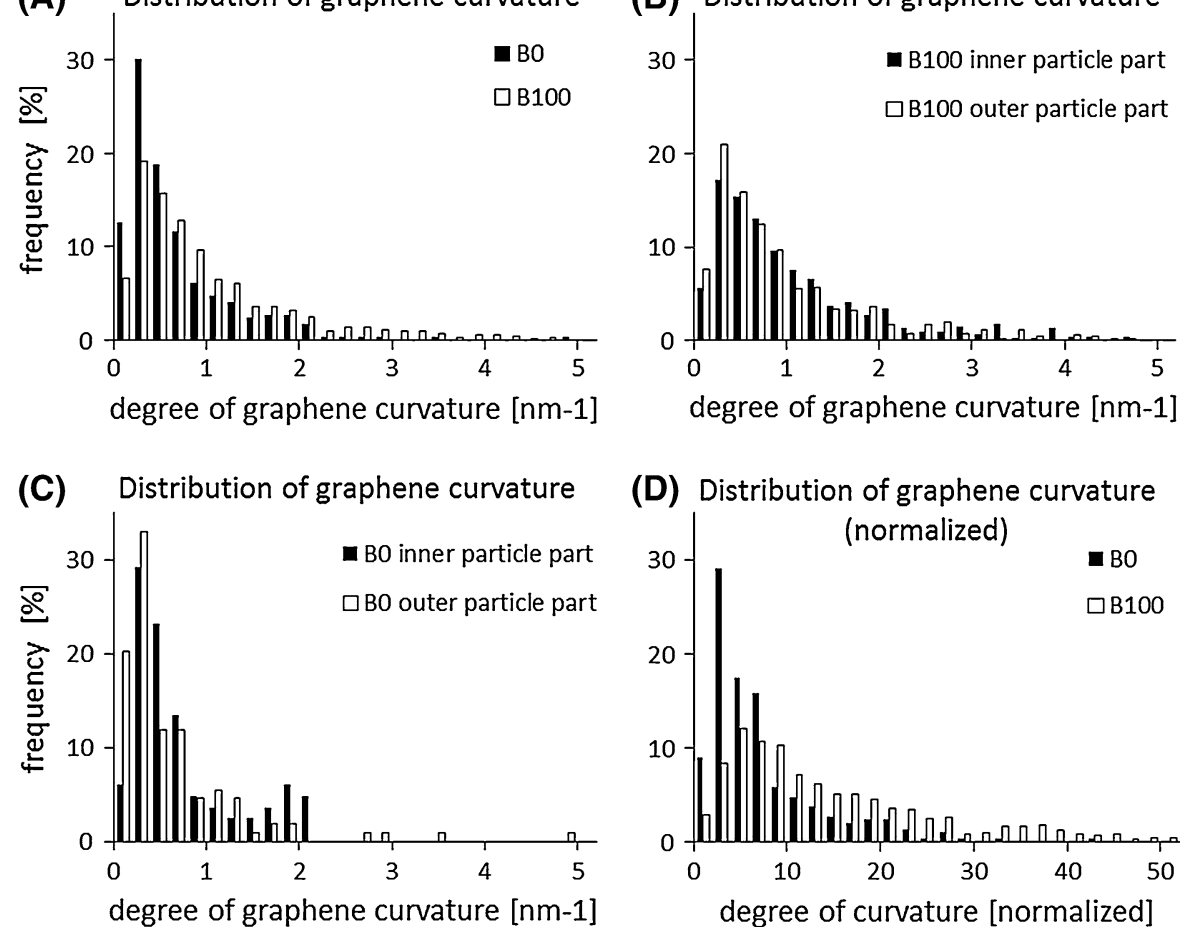

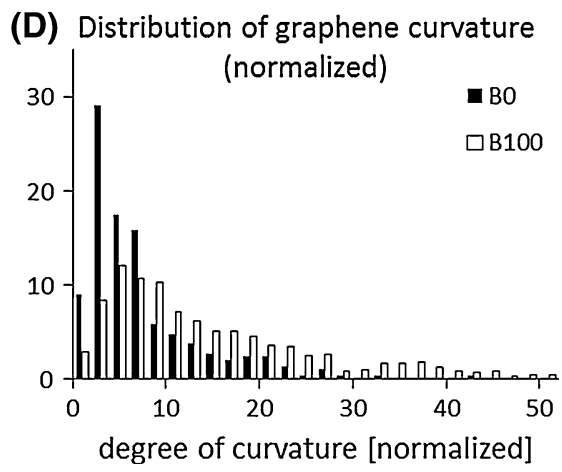

combustion chamber with fuel-rich diffusion flames (e.g., Wang et al. 2000; Rakopoulos et al. 2008) and promotes the oxidation of soot that has already been formed. Moreover, aromatics, which are considered as soot precursors, are absent in biodiesel fuels, which is a reason for lower soot emissions. Müller et al. (2006), measuring with differential mobility analyzers in a soot furnace, showed that the oxidation velocity of biodiesel soot was up to six times higher than that of diesel soot.

On the other hand, carbon-oxygen functional groups like $\mathrm{C}=\mathrm{O}, \mathrm{C}-\mathrm{O}-\mathrm{C}$ or $\mathrm{C}-\mathrm{OH}$, expected to be very reactive sites, were detected by Müller et al. (2006) on diesel soot samples. The slower oxidation rate of diesel soot is attributed by the above authors to the oxidation of the remaining $\mathrm{C}-\mathrm{C}$ bondings of the carbon atoms within the particles.

The presence of a relatively more amorphous biodiesel-derived soot nanostructure has been described and ascribed to the prevalence of a coalescence growth mechanism over a 'Hydrogen Abstraction Carbon Addition' (HACA) mechanism during soot growth. While formation of heavy PAH species leads to an amorphous structure through the coalescence growth mechanism, light acetylene $\left(\mathrm{C}_{2} \mathrm{H}_{2}\right)$ addition to the radical sites of PAH species leads to formation of graphitic structures through the HACA mechanism.

\section{Conclusions}

The detailed macroscopic, optical microscopic, SEM, and HRTEM investigation of PM deposited in the B100-, B20-, and B0-DPFs lead to the following conclusions:

1. The B100-DPF contains significantly less soot deposits than B20 and B0. In the B20- and B0DPFs, soot forms a soot cake 200-270- $\mu$ m thick.

2. The B100-DPF contains significantly more abundant ash deposits, richer in $\mathrm{Ca}-\mathrm{S}-$ and, to a lesser degree, P-bearing compounds compared to B20, which in turn shows the same trend against the B0. These differences in the amount and chemical composition of ash among the three fuel types imply that the RME-biofuel contributes significantly to ash production. Note that although biofuel composition varies from supplier to supplier, the RME-fuel used in this study is considered typical for Europe, and especially for the 
Swiss market. In all DPFs, the size of ash PM ranges mostly between 50 and $300 \mathrm{~nm}$.

3. In all three DPFs, ash deposits occur on the inlet DPF surface and on the inlet channel walls. In B20- and B0-DPFs, ash deposits, often intermingled with gasket- and insulating mat-derived fibers, occur underneath the soot cake. In the B100-DPF, ash also occurs at the plugged ends of inlet channels. The presence of ash at the plugged ends can be ascribed to the high mobility of the ash, due to its very low degree of compaction. The latter is favored by low soot production. It seems that the ash/soot ratio in the B100-DPF is such that it promotes ash transport to the plugged ends. Metallic $\mathrm{Fe}-\mathrm{Cr}-\mathrm{Ni}$ fragments (micrometers- to a few tens of nanometers large) within the ash of all DPFs are due to engine wear.

4. Pt particles (50-400 $\mathrm{nm}$ large) in the ash indicate that the DOC upstream of the DPF shows aging effects. SEM imaging of the DOC reveals the presence of abundant radial cracks on the coating layer, which allow embedded Pt particles to escape, thus confirming the aging assumption.

5. The size distribution of primary soot particles for B100 and B0 soot reveals that combustion of the biofuel produces slightly smaller soot particles than diesel fuel. This inference denotes that B100 soot can be slightly more prone to oxidation than soot from B0, as far as the size of primary particles is concerned.

6. Comparison of the soot nanostructure between B100 and B0 soot in terms of length, curvature, separation distance of the graphene layers, as well as degree of crystalline order (the most critical parameters related to the oxidative reactivity of soot) reveals the following:

(a) Biofuel-derived soot contains a higher percentage of short graphene lamellae than diesel soot.

(b) Biofuel graphene lamellae display, overall, a higher curvature than those from diesel soot.

(c) The separation distance between regularly successive graphene lamellae in diesel soot is slightly shorter than that in biofuel soot $(0.365-0.372 \mathrm{~nm}$ in diesel soot versus $0.373-0.381 \mathrm{~nm}$ in biofuel), and thus is closer to the $0.335 \mathrm{~nm}$ lattice parameter in graphite.

(d) Diesel soot contains more numerous and thicker graphene crystallites compared to the biofuel soot, thus showing a higher degree of crystalline order.

Based on the above parameters related to the soot nanostructure, including the size of the primary particles, the biofuel soot is more easily oxidized than diesel soot, not only during early soot formation, but also during and after considerable particle growth. This is a new inference of the present study and is in line with the suggestion of previous studies supporting the higher oxidation capacity of biodiesel-derived soot (Vander Wal et al. 2010; Song et al. 2006; Lamharess et al. 2011 and references therein). It seems that the presence of reactive carbon-oxygen functional groups like $\mathrm{C}=\mathrm{O}, \mathrm{C}-\mathrm{O}-\mathrm{C}$, or $\mathrm{C}-\mathrm{OH}$ reported by Müller et al. (2006) on diesel soot samples is weighing less for the oxidative behavior of soot compared to the nanostructural parameters described above.

Acknowledgments The authors would like to thank the Swiss Federal Office of Energy (SFOE) for financial support, as well as Prof. J. Czerwinski, Biel, for his assistance during the experimental part. The paper benefited from the constructive comments of two anonymous reviewers.

\section{References}

Agarwal AK (2007) Biofuels (alcohols and biodiesel) applications as fuels for internal combustion engines. Prog Energy Combust Sci 33:233-271

Bensaid S, Marchisio DI, Russo N, Fino D (2009) Experimental investigation of soot deposited in diesel particulate filters. Catal Today 147:S295-S300

Boehman AL, Song J, Alam M (2005) Impact of biodiesel blending on diesel soot and the regeneration of particulate filters. Energy Fuels 19:1857-1864

Britton N, Sutton M, Otterholm B, Tengstrom P, Frennfelt C, Walker A, Murray I (2004) Investigations into lubricant blocking of diesel particulate filters. SAE Technical Paper 2004-01-3013

Cataldo F (2002) The impact of fullerene-like concept in carbon black science. Carbon 40:157-162

Hays MD, Vander Wal RL (2007) Heterogeneous soot nanostructure in atmospheric and combustion source aerosols. Energy Fuels 21:801-811

Jung H, Kittelson DB, Zachariah MR (2006) Characteristics of SME biodiesel-fueled diesel particle emissions and the kinetics of oxidation. Environ Sci Technol 40(16):49494955 
Kim DH, Wang CH (2007) HRTEM Study of diesel soot collected from diesel particulate filters. Carbon 45:70-77

Knauer M, Schuster ME, Su D, Schlögl R, Niessner R, Ivleva NP (2009) Soot structure and reactivity analysis by Raman microspectroscopy, temperature-programmed oxidation, and high-resolution transmission electron microscopy. J Phys Chem A 113:13871-13880

Knothe G (2008) 'Designer' biodiesel: optimizing fatty ester composition to improve fuel properties. Energy Fuels 22:1358-1364

Lamharess N, Millet CN, Starck L, Jeudy E, Lavy J, Da Costa P (2011) Catalysed diesel particulate filter: study of the reactivity of soot arising from biodiesel combustion. Catal Today 176:219-224

Lapuerta M, Armas O, Rodríguez-Fernández J (2008) Effect of biodiesel fuels on diesel engine emissions. Prog Energy Combust Sci 34:198-223

Liati A, Dimopoulos Eggenschwiler P (2010) Characterisation of particulate matter deposited in diesel particulate filters: visual and analytical approach in macro-, micro- and nanoscales. Combust Flame 157:1658-1670

Liati A, Dimopoulos Eggenschwiler P, Czerwinski J, Bonsack P, Hermle S (2011) Comparative studies of particles deposited in diesel particulate filters operating with biofuel, diesel fuel and fuel blends. SAE Technical Paper 2011-240102

Liati A, Dimopoulos Eggenschwiller P, Müller Gubler E, Schreiber D, Aguirre M (2012) Investigation of diesel ash particulate matter: a scanning electron microscope and transmission electron microscope study. Atmos Environ 49:391-402

Müller JO, Su DS, Jentoft RE, Kröhnert J, Jentoft FC, Schlögl R (2005) Morphology-controlled reactivity of carbonaceous materials towards oxidation. Catal Today 102(103): 259-265

Müller JO, Su DS, Jentoft RE, Wild U, Schlögl R (2006) Diesel engine exhaust emission: oxidative behavior and microstructure of black smoke soot particulate. Environ Sci Technol 40:1231-1236

Müller JO, Su DS, Wild U, Schlögl R (2007) Bulk and surface structural investigations of diesel engine soot and carbon black. Phys Chem Chem Phys 9:4018-4025

Nishi K, Korematsu K, Tanaka J (2004) Potential of rapeseed oil as diesel engine fuel. SAE Technical Paper 2004-01-1858

Rakopoulos CD, Rakopoulos DC, Hountalas DT, Giakoumis EG, Andritsakis EC (2008) Performance and emissions of bus engine using blends of diesel fuel with bio-diesel of sunflower or cottonseed oils derived from Greek feedstocks. Fuel 87:147-157

Sappok A, Wong V (2010) Ash effects on diesel particulate filter pressure drop sensitivity to soot and implications for regeneration frequency and DPF control. SAE Int J Fuels Lubr 3:380-396

Schreiber D, Forss A M, Mohr M and Dimopoulos P (2007) Particle characterisation of modern $\mathrm{CNG}$, gasoline and diesel passenger cars. SAE (Society of Automotive Engineers) Paper 2007-24-0123, Italy

Schuster ME, Hävecker M, Arrigo R, Blume R, Knauer M, Ivleva NP, Su DS, Niessner R, Schlögl R (2011) Surface sensitive study to determine the reactivity of soot with the focus on the European emission standards IV and VI. J Phys Chem A 115:2568-2580

Song J, Alam AL, Boehman U, Kim U (2006) Examination of the oxidation behavior of biodiesel soot. Combust Flame 146:589-604

Song J, Alam M, Boehman AL (2007) Impact of alternative fuels on soot properties and DPF regeneration. Combust Sci Technol 179:1991-2037

Su DS, Jentoft RE, Müller JO, Jentoft RE, Rothe D, Jacob E, Schlögl R (2004a) Fullerene-like soot from Euro-IV diesel engine: consequences for catalytic automotive pollution control. Top Catal 30(31):241-245

Su DS, Jentoft RE, Müller JO, Rothe D, Jacob E, Simpson CD et al (2004b) Microstructure and oxidation behaviour of Euro IV diesel engine soot: a comparative study with synthetic model soot substances. Catal Today 90:127-132

Tsolakis A, Megaritis A, Wyszynski ML, Theinno K (2007) Engine performance and emissions of a diesel engine operating on diesel-RME (rapeseed methyl ester) blends with EGR (exhaust gas recirculation). Energy 32:20722080

Twigg MV (2007) Progress and future challenges in controlling automotive exhaust gas emissions. Appl Catal B 70:2-15

Vaaraslahti K, Keskinen J, Giechaskiel B, Solla A, Murtonen T, Vesala $H$ (2005) Effect of lubricant on the formation of heavy-duty diesel exhaust nanoparticles. Environ Sci Technol 39:8497-8504

Vander Wal RL, Tomasek AJ, Pamphlet MI, Taylor CD, Thompson WK (2004) Analysis of HRTEM images for carbon nanostructure quantification. J Nanopart Res 6:555-568

Vander Wal RL, Bryg VM, Hays MD (2010) Fingerprinting soot (towards source identification): physical structure and chemical composition. Aerosol Sci 41:108-117

Wang WG, Lyons DW, Clark NN, Gautam M, Norton PM (2000) Emissions from nine heavy trucks fuelled by diesel and biodiesel blend without engine modification. Environ Sci Technol 34(6):933-939

Watson SAG (2010) Lubricant-derived ash-in engine sources and opportunities for reduction. $\mathrm{PhD}$ Thesis, Massachusetts Institute of Technology, $235 \mathrm{pp}$

Wu F, Wang J, Chen W, Shuai S (2008) Effects of different biodiesels and their blends with oxygenated additives on emissions from a diesel engine. SAE Technical Paper 2008-01-1812

Yehliu K, Vander Wal RL, Boehman AL (2011) Development of an HRTEM image analysis method to quantify carbon nanostructure. Combust Flame 158:1837-1851

Yezerets A, Currier NW, Eadler HA, Suresh A, Madden PF (2003) Investigation of the oxidation behavior of diesel particulate matter. Catal Today 88:17-25

Zabetta E, Hupa M, Niemi S (2006) Bio-derived fuels may ease the regeneration of diesel particulate traps. Fuel $85: 2666-2670$

Zhu W, Miser DE, Geoffrey Chan W, Hajaligol MR (2004) Characterisation of combustion fullerene soot, $\mathrm{C}_{60}$, and mixed fullerene. Carbon 42:1463-1471 